\title{
A Novel Derivatization Ultraviolet Spectrophotometric Method for the Determination of Dihydroartemisinin using $p$ - Nitroaniline
}

\author{
Chinedum $\mathbf{P}$ Babalola $^{1^{*}}$, Isaac Oluwalana1, Olayinka A Kotila ${ }^{1}$, Olajire A \\ Adegoke ${ }^{1}$, Yetunde T Kolade ${ }^{2}$ and Sunday $\mathrm{J} \mathrm{Ameh}^{3}$ \\ ${ }^{1}$ Department of Pharmaceutical Chemistry, Faculty of Pharmacy, University of Ibadan, Ibadan, Nigeria, ${ }^{2}$ Reckitt Benckiser UK \\ Ltd, Wellcroft House, Wellcroft Road, Slough, Berkshire, SL1 4AQ, UK, ${ }^{3}$ Department of Medicinal Chemistry and Quality \\ Control, National Institute for Pharmaceutical Research and Development (NIPRD), PMB 21, Garki, Idu Industrial Area, Abuja, \\ Nigeria.
}

*For correspondence: Email: peacebab2001@yahoo.com; Tel: +234-805-522-4989

Received: 17 January 2013

Revised accepted: 3 November 2013

\begin{abstract}
Purpose: To develop a novel ultraviolet (UV)-spectrophotometric method for the determination of dihydroartemisinin (DHA) in tablets using p-nitroaniline (PNA) as a derivatizing agent.

Methods: Derivatization was based on the reaction between methanol solutions of dihydroartemisinin $(D H A)$ and p-nitroaniline (PNA) in acid medium $(1 \mathrm{M} \mathrm{HCl})$ at elevated temperature and for a short reaction time. Optimal detector response was obtained within 15 min when the reaction was carried out at $90^{\circ} \mathrm{C}$ in a molar ratio of 2:1 (DHA:PNA). The method used for analysis was validated and a linear calibration curve constructed in the range of $30-100 \mu \mathrm{g} / \mathrm{mL}$ for the reaction mixture at an absorbance of $290 \mathrm{~nm}$.

Results: Separation of adduct from PNA was better achieved on reversed phase thin layer chromatography (TLC) using acetonitrile : water (60:50) or on high performance liquid chromatography (HPLC) with retention times of $2.8 \mathrm{~min}$ for PNA and $5.8 \mathrm{~min}$ for the adduct. The limit of detection was 6 $\mu \mathrm{g} / \mathrm{mL}$. The method was precise and accurate in the range $100.70-100.96 \%$, with intraday and interday precisions of less than $2 \%$ at concentrations of 40 and $80 \mu \mathrm{g} / \mathrm{mL}$, respectively. The new method was applied to the assay of two brands of dihydroartemisinin tablets with accuracy similar to that of the International Pharmacopoeia (IP) UV-spectrophotometric method $(p>0.05)$.

Conclusion: The derivatization method is simple, direct, devoid of dilutions and inexpensive in terms of reagent requirements and analyte volume, and has a shorter reaction time, cpmpared with IP method. Based on the foregoing, the method can be adopted as an alternative to the official assay method for routine quality control of dihydroartemisinin tablets.
\end{abstract}

Keywords: Derivatization, Ultraviolet spectrophotometry, Dihydroartemisinin, p-Nitroaniline, Analysis, Assay, Quality control

Tropical Journal of Pharmaceutical Research is indexed by Science Citation Index (SciSearch), Scopus, International Pharmaceutical Abstract, Chemical Abstracts, Embase, Index Copernicus, EBSCO, African Index Medicus, JournalSeek, Journal Citation Reports/Science Edition, Directory of Open Access Journals (DOAJ), African Journal Online, Bioline International, Open-J-Gate and Pharmacy Abstracts

\section{INTRODUCTION}

Dihydroartemisinin is a semi-synthetic derivative and the major metabolite of the parent drug artemisinin (Qinghaosu) obtained from the plant
Artemisia annua [1]. Owing to the increase in drug resistance, the World Health Organization (WHO) in 2005 recommended that all uncomplicated $P$. falciparum infections be treated with artemisinin-based combination therapies (ACTs) but DHA and the other artemisinin 
derivatives lack chromophores, and therefore are UV-transparent and require derivatization procedures before UV-spectrophotometry can be applied [1].

Analytical procedures for the detection and assay of DHA and the other artemisinin-based drugs have been developed during the last 25 years but these either involve multiple dilution stages, long reaction hours or costly gadgets. In this paper, we report a novel UV-spectrophotometric method for the assay of Dihydroartemisinin Tablets using $p$-nitroaniline as the derivatizing agent. The new method is simple, direct, devoid of dilutions and inexpensive in reagents and analyte volumes and has a shorter reaction time with minimal instrumentation. The method compares well with the current International Pharmacopoeia IP (2003) method ( $p>0.05)$. Consequently, we deem the method suitable for routine quality control analysis, especially routine field assay of DHA-based drugs.

\section{EXPERIMENTAL}

\section{Reagents and chemicals}

Methanol, ethyl acetate, chloroform, acetone, hydrochloric acid, $p$-nitroaniline, (BDH, UK), acetonitrile (Philips and Hams England), hexane (Hopkins and Williams, Birmingham, England), liquid paraffin, distilled water, Alaxin ${ }^{\circledR} 60 \mathrm{mg}$ (dihydroartemisinin tablets, GVS Labs, India) and Cotecxin $^{\circledR} 60 \mathrm{mg}$ (dihydroartemisinin tablets, Jiaxing Nanhu Pharm, China).

\section{Equipment}

UV-visible spectrophotometer (Unicam Aurora, Helios Scan Software v 1.1, Pye Unicam, England), Buck Scientific Fourier transform infrared spectrophotometer model M500, HPLC (HP series 1100), Mettler analytical balance H80 (U.K), water bath, UV lamp light sources, vortex mixer.

\section{Derivatization}

The derivatization reaction was based on the reaction between methanol solutions of dihydroartemisinin (DHA) and p-nitroaniline (PNA) in acid medium $(1 \mathrm{M} \mathrm{HCl})$ at the elevated temperature of $90^{\circ} \mathrm{C}$.

Stock solutions of DHA $(100 \mu \mathrm{g} / \mathrm{mL})$ and PNA (500 $\mu \mathrm{g} / \mathrm{mL})$ were prepared for the derivatization reaction. In order to determine the optimum conditions for the derivatization reaction, the following critical response parameters were optimized; (i) the strength of $\mathrm{HCl}$ required for the reaction (ii) stoichiometric ratio of drug - reagent (DHA-PNA) (iii) temperature of the reaction and (iv) reaction time

\section{Optimization of acid reaction condition}

Aliquot volumes $(1 \mathrm{ml})$ each of $0.5,1,2,3,4$ and $5.0 \mathrm{M} \mathrm{HCl}$ were put into identical test-tubes with $1 \mathrm{~mL}$ of DHA stock solution $(100 \mu \mathrm{g} / \mathrm{mL})$ and 1 $\mathrm{mL}$ PNA stock solution $(500 \mu \mathrm{g} / \mathrm{mL})$ added to each test tube and vortexed for $10 \mathrm{~s} .1 \mathrm{~mL}$ of methanol in a similar test tube served as blank. The test tubes were incubated in a water bath at $60{ }^{0} \mathrm{C}$ for $45 \mathrm{~min}$. Again $1 \mathrm{~mL}$ each of DHA, PNA stock solutions and $0.2 \mathrm{~mL} 1 \mathrm{M} \mathrm{HCl}$ were added in a test tube and vortexed for $10 \mathrm{~s}$. The test tube was incubated in a water bath maintained at 60 ${ }^{0} \mathrm{C}$ for $45 \mathrm{~min}$. After cooling to room temperature $\left(25^{\circ} \mathrm{C}\right), 4 \mathrm{~mL}$ of methanol was added and the UV spectrum recorded on a UV-Visible spectrophotometer (Unicam Aurora, Helios Scan Software v 1.1, Pye Unicam, England) between $190-800 \mathrm{~nm}$.

\section{Determination of the stoichiometric ratio of drug - reagent (DHA-PNA)}

Equi-molar solutions (0.001M) of DHA (0.0284 g in $100 \mathrm{~mL})$ and PNA (0.0138 $\mathrm{g}$ in $100 \mathrm{~mL})$ were prepared in methanol. Into five different test tubes each containing $0.2 \mathrm{~mL}$ of $1 \mathrm{M} \mathrm{HCl}, 0.3$, $0.3,0.3,0.6$ and $0.9 \mathrm{~mL}$ respectively of DHA were added and vortexed for 10 seconds. Thereafter $0.3,0.6,0.9,0.3$, and $0.3 \mathrm{~mL}$ respectively of PNA were added and again vortexed for 10 seconds. Five test tubes serving as controls and each containing same constituents except for DHA (which was replaced with methanol) were also prepared. All ten test tubes were incubated in a water bath at $60{ }^{\circ} \mathrm{C}$ for $45 \mathrm{~min}$. The test tubes were left to cool at room temperature and $1 \mathrm{~mL}$ of methanol added. 0.5 $\mathrm{mL}$ was withdrawn into a tube, diluted with $3 \mathrm{~mL}$ of methanol and absorbance determined at 290 $\mathrm{nm}$ using a UV-visible spectrophotometer.

\section{Optimization of reaction temperature and time}

The temperature and time for optimum reaction were determined. Reaction mixtures containing $0.6 \mathrm{~mL}$ of DHA $\left(10^{-3} \mathrm{M}\right), 0.3 \mathrm{~mL}$ of PNA $\left(10^{-4} \mathrm{M}\right)$, and $0.2 \mathrm{~mL}$ of $1 \mathrm{M} \mathrm{HCl}$ were vortexed for $10 \mathrm{~s}$ and incubated at varying temperatures ranging from 30 to $100{ }^{\circ} \mathrm{C}$ for $30 \mathrm{~min}$. Methanol $(1 \mathrm{~mL})$ was added to each test tube to terminate the reaction and aliquots $(0.5 \mathrm{~mL})$ were withdrawn into sample tubes and again diluted to $3 \mathrm{~mL}$ with methanol and the absorbance of each sample tube was taken at $290 \mathrm{~nm}$. Each reaction was 
carried out in triplicate. The optimal reaction time followed the same procedure. Reaction tubes were incubated at $90{ }^{\circ} \mathrm{C}$ and reaction was terminated by adding $1 \mathrm{~mL}$ methanol at $5,10,15$, 30,45 and $60 \mathrm{~min}$, respectively. $0.5 \mathrm{~mL}$ of each test tube was withdrawn, diluted to $3 \mathrm{~mL}$ with methanol and absorbance reading taken at 290 $\mathrm{nm}$. The test was also carried out in triplicate.

\section{Determination of $\mathbf{R f}$ values in different solvent systems}

The aim was to compare the $R_{f}$ values of the DHA-PNA adduct and the reagent in various solvent systems and to confirm the evidence of a new adduct formation. To $1 \mathrm{~mL}$ DHA (100 $\mu \mathrm{g} / \mathrm{mL}$ ), $0.2 \mathrm{~mL} 1 \mathrm{M} \mathrm{HCL}$ and $0.1 \mathrm{~mL}$ PNA (500 $\mu \mathrm{g} / \mathrm{mL}$ ) solutions were added in a tube and vortexed for $10 \mathrm{~s}$. In a second tube $1 \mathrm{~mL}$ of methanol, $0.2 \mathrm{~mL} 1 \mathrm{M} \mathrm{HCL}$ and $0.1 \mathrm{~mL}$ PNA solution $(500 \mu \mathrm{g} / \mathrm{mL})$ were added and vortexed for $10 \mathrm{~s}$. The two test tubes were then incubated at $90{ }^{\circ} \mathrm{C}$ for $15 \mathrm{~min}$. The test tubes were cooled briefly and $3 \mathrm{~mL}$ of ethyl acetate and $3 \mathrm{~mL}$ of water were added and mixed again. From the ethyl acetate layer of each test tube about $5 \mu \mathrm{L}$ was removed with capillary tube and spotted on silica gel plates separately. The following solvent systems were adopted during the investigation:

Normal phase - (i) ethyl acetate: methanol (6:4) (ii) ethyl acetate: hexane (5:5) (iii) chloroform: toluene: acetone (65:25:10) (iv) chloroform: methanol (95:5) (v) methanol: strong ammonia (100:50), (vi) liquid paraffin: ether (5:5).

Reverse phase - Acetonitrile: water (60:40, $40: 60,45: 50,60: 50,50: 50$ and 55:50)

\section{IR Investigation}

The aim of the investigation was to confirm the formation of a new chemical entity by the reaction between $p$-nitroaniline and dihydroartemisinin. To $5 \mathrm{~mL}$ of $1 \mathrm{mg} / \mathrm{mL}$ DHA solution, $0.2 \mathrm{~mL} 1 \mathrm{M} \mathrm{HCl}$ and $2.5 \mathrm{~mL}$ of $1 \mathrm{mg} / \mathrm{mL}$ PNA solution were added in five test tubes and vortexed for $10 \mathrm{~s}$. The test tubes were incubated at $90{ }^{\circ} \mathrm{C}$ for $15 \mathrm{~min}$ and thereafter allowed to cool to room temperature. To each test tube, $3 \mathrm{~mL}$ of dichloromethane was added and mixed, and same volume of water was added and mixed again. The dichloromethane layers were carefully withdrawn into petri dishes, using a pipette, and allowed to dry in air. The powdery adduct was further dried in an oven at $50{ }^{\circ} \mathrm{C}$ and this powder along with the PNA powder were scanned on an IR spectrophotometer.

\section{Determination of Rt value in specified solvent system}

The aim of the investigation was to find a suitable column and solvent system that will separate the DHA-PNA adduct and p-nitroaniline (PNA). The adduct was prepared using $1 \mathrm{~mL}$ DHA (100 $\mu \mathrm{g} / \mathrm{mL}$ ) solution, $0.2 \mathrm{~mL} 1 \mathrm{M} \mathrm{HCl}$ and $0.1 \mathrm{~mL}$ PNA $(500 \mu \mathrm{g} / \mathrm{mL})$ solution vortexed for $10 \mathrm{~s}$ and the reagent was made using $1 \mathrm{~mL}$ of methanol, 0.2 $\mathrm{mL} 1 \mathrm{M} \mathrm{HCl}$ and $0.1 \mathrm{~mL}$ PNA solution (500 $\mu \mathrm{g} / \mathrm{mL}$ ) vortexed for $10 \mathrm{~s}$. Both tubes were incubated at $90{ }^{\circ} \mathrm{C}$ for $15 \mathrm{~min}$, cooled to room temperature and $3 \mathrm{~mL}$ of ethyl acetate was added to each mixture, followed by addition of 3 $\mathrm{mL}$ of water. From the ethyl acetate layer, $100 \mu \mathrm{L}$ were removed into separate sample bottles, allowed to dry in air and then covered and stored at $-20{ }^{0} \mathrm{C}$ prior to HPLC analysis. For HPLC analysis, each sample tube had $0.5 \mathrm{~mL}$ methanol added into it and $20 \mu \mathrm{L}$ was injected into the column.

\section{Method validation}

At the optimal analytical conditions described above, the calibration lines were obtained using standard solutions of $30,40,50,60,80$ and 100 $\mu \mathrm{g} / \mathrm{mL}$. DHA. Linear regression analysis was used to calculate the slope, intercept and coefficient of determination $\left(r^{2}\right)$ of each calibration line. The limit of detection was computed from the calibration equation as the analyte concentration giving a signal equal to the blank signal plus three standard deviations of the blank [18]. The accuracy and precision of the method were determined as documented by the United States Pharmacopoeia (USP) [17]: Multiple analysis $(n=5)$ of DHA at two different known concentrations (40 and $80 \mu \mathrm{g} / \mathrm{mL}$ ) were analysed daily (intra-day) and repeated for three days (inter-day) using the optimized analytical method. The results were computed as mean \pm standard deviation for both intra-day and interday analysis. Mean value within $15 \%$ of the actual concentration value indicates the accuracy of the method and mean value within $15 \%$ of the coefficient of variation ascertains the precision of the method.

\section{Assay of dosage form}

Two brands of DHA tablets, Cotecxin ${ }^{\circledR}$ (60mg) and Alaxin ${ }^{\circledR}$ (60mg) were used for the assay. An amount of powdered tablets (Alaxin ${ }^{\circledR}$ ) equivalent to $10 \mathrm{mg}$ of DHA was weighed and dissolved in $10 \mathrm{~mL}$ of methanol. After $15 \mathrm{~min}$, the suspension was filtered to remove the excipients and the 
filtrate was labeled as the stock solution (1 $\mathrm{mg} / \mathrm{mL})$. A portion of this stock solution $(2 \mathrm{~mL})$ was measured into a $20 \mathrm{~mL}$ volumetric flask, diluted to volume with methanol to give a 100 $\mu \mathrm{g} / \mathrm{mL}$ working solution. Then $0.5 \mathrm{~mL}$ of the Alaxin ${ }^{\circledR}$ working solution was measured into four different test tubes and diluted to $1 \mathrm{~mL}$ with methanol to give a $50 \mu \mathrm{g} / \mathrm{mL}$ solution. To this, $0.2 \mathrm{~mL}$ of $1 \mathrm{M} \mathrm{HCl}$ was added and vortexed, followed by $0.1 \mathrm{~mL}$ of $500 \mu \mathrm{g} / \mathrm{mL}$ PNA solution and vortexed again. The tubes were incubated at $90^{\circ} \mathrm{C}$ for 15 minutes. The reaction was quenched with $3 \mathrm{~mL}$ of methanol and absorbance taken at $290 \mathrm{~nm}$. The assay procedure was repeated for Cotecxin $^{\circledR}$ tablets and these two tablets were also assayed using IP (2003) method. Both methods were compared and a two-tailed probability value $(p \leq 0.05)$ was considered to be significant.

\section{Statistical analysis}

Statistical analysis was carried out by Student ttest (using Microsoft Excel 2007) when comparing the two assay methods with significance value set at $p \leq 0.05$.

\section{RESULTS}

\section{Stoichiometric ratio of drug - reagent (DHA- PNA)}

The coupling reaction of dihydroartemisinin and p-nitroaniline solution was optimum at ratio $2: 1$ of drug to reagent (Figure 1) and formed an intense yellow adduct under all coupling conditions tested.

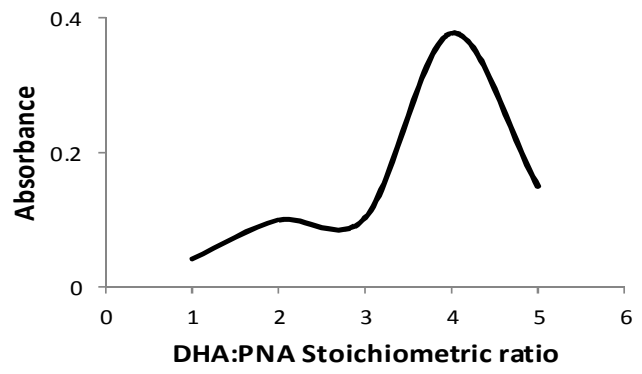

Figure 1: Plot of absorbance against DHA:PNA

stoichiometric ratio $(1=1: 1 ; 2=1: 2 ; 3=1: 3 ; 4=2: 1 ; 5$ $=3: 1$ DHA:PNA respectively)

\section{Optimum reaction conditions, temperature and time}

The spectrum of the adduct indicated a hyperchromic shift with respect to that of the reagent with peaks at 205, 230 and $380 \mathrm{~nm}$. The strength of $\mathrm{HCl}$ ideal for the reaction was $1 \mathrm{M}$ and the absorbance of the adduct was highest at $90^{\circ} \mathrm{C}$ and $15 \mathrm{~min}$ (Figure 2).

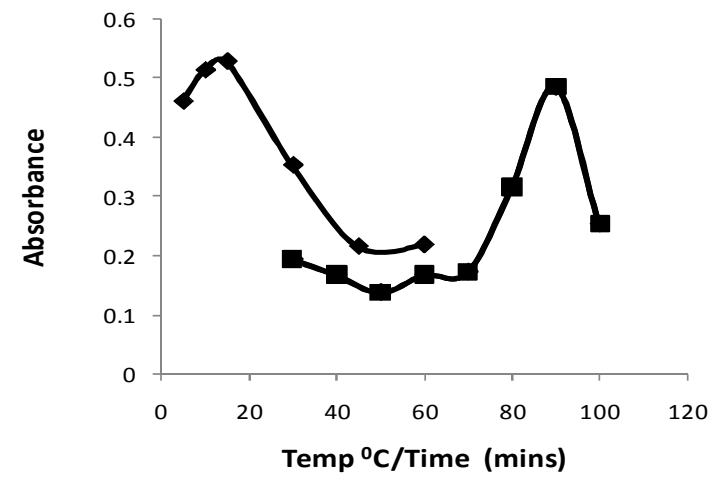

Figure 2: Plot of absorbance against temperature $\left({ }^{0} \mathrm{C}\right.$, $\downarrow)$ and time (min, $\mathbf{\square})$

Chromatographic analysis showed that reversed phase systems gave a better separation of adduct from the reagent on both TLC and HPLC with acetonitrile:water ratios of 60:50, 40:50 and 55:50 giving good separation. The IR spectrum of the dried adduct was different from that of the reagent, thus confirming the success of the derivatization reaction (Figure 3 ).

Linear regression equation for the calibration line under optimal reaction conditions is $y=0.0023 x$ -0.0018 with $r^{2}$ of 0.9987 . The limit of detection was $5.9 \mu \mathrm{g} / \mathrm{mL}$. Validation studies show that the new method is precise and accurate. The intraday and interday precision was in the range $1.13-1.52 \%$ and $0.84-1.13 \%$ respectively. The mean percentage accuracy of the method was in the range $100.79-100.96 \%$.

Comparative analysis of the two brands of dihydroartemisinin by the official (IP 2003) and the new method is shown in Table 1. Using student t-test there is no significant difference between the official and the new method reported $(p=0.08)$.

Table 1: Content (mean \pm SD) of dihydroartemisinin tablets obtained by the two assay methods

\begin{tabular}{lccc}
\hline Brand & $\begin{array}{c}\text { Proposed } \\
\text { method } \\
(\% \text { w/w) }\end{array}$ & $\begin{array}{c}\text { Official } \\
\text { method } \\
(\% w / w)\end{array}$ & $\boldsymbol{P}$ value \\
\hline Alaxin $\AA$ & $94.31 \pm 2.12$ & $95.47 \pm$ & 0.293779 \\
& & 0.67 & \\
Cotecxin $\circledast$ & $97.35 \pm 0.50$ & $96.37 \pm$ & 0.082566 \\
& & 0.58 & \\
\hline
\end{tabular}

\section{DISCUSSION}

Figure 3 shows the IR spectrum of the reagent PNA alone and when viewed simultaneously with the spectrum of the adduct, DHA-PNA. The adduct formed by the reaction of dihydroartemisinin with $p$-nitroaniline has an IR spectrum with prominent peaks in the fingerprint region $\left(1500-600 \mathrm{~cm}^{-1}\right)$ that clearly differ from those of 


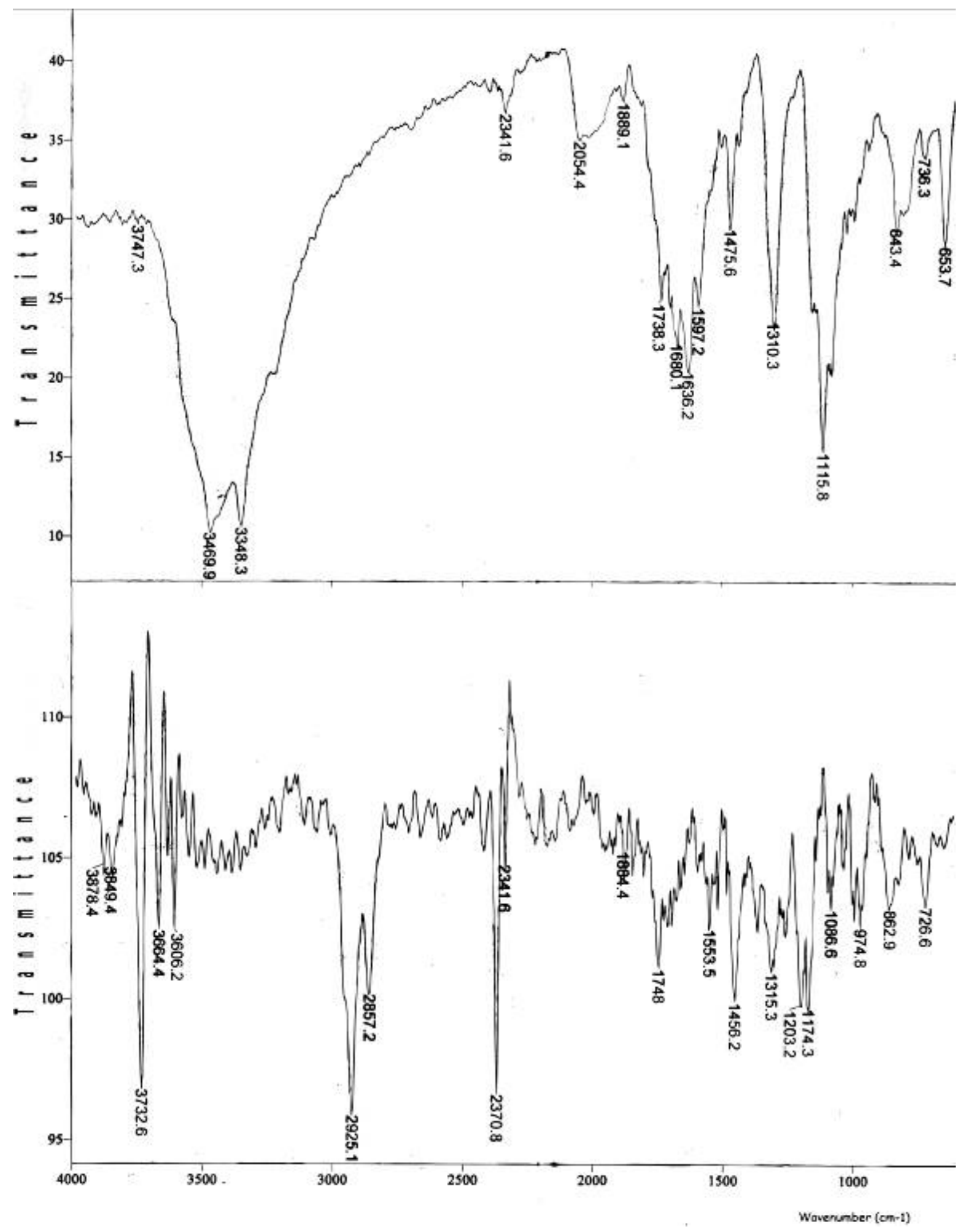

Figure 3: IR spectrum of PNA and DHA-PNA adduct viewed simultaneously 
<smiles>C[C@@H]1CC[C@H]2[C@@H](C)[C@H](O)OC3O[C@]4(C)CC[C@@H]1[C@]32OO4</smiles>

DHA<smiles>CC(=O)C1=COCCC1</smiles>

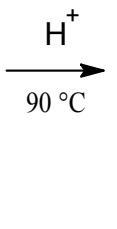

Acid decomposition product of DHA

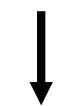<smiles>C/C(=N\c1ccc([N+](=O)[O-])cc1)C1=COC2(O)[C@H](C(C)(C)C(=O)O)CC[C@@H](C)[C@H]2C1</smiles>

PNA - DHA adduct

Figure 4: Proposed mechanism of reaction between DHA and PNA

the reagent spectrum. Notably, the UV absorption spectrum of adduct showed a hyperchromic shift relative to that of the reagent (not included). A possible mechanism of reaction for the adduct formation is, first, acid decomposition of DHA to form a product containing a carbonyl function which in turn reacts with the amine to generate an imine adduct. The presence of hyper-conjugation of bonds in the adduct thus formed accounts for the intense yellow color of the new compound (Figure 4). These considerations collectively suggest that the derivatization was successful and that a new chemical entity was formed. Indeed both the TLC and HPLC outcomes further confirm the formation of an adduct.

Using Job's method of continuous variation, a plot of absorbance against drug-reagent stoichiometric ratio showed maximum absorbance at a drug-reagent ratio of 2:1. While the possibility of multiple products can be suggested, TLC results did not indicate this. However, the HPLC separation on Hypersil column gave two separate peaks suggesting the formation of two main products. This corroborates the stoichiometric ratio determination. The optimum temperature and time for the reaction were $90{ }^{\circ} \mathrm{C}$ and $15 \mathrm{~min}$, respwctively which compares with the reaction of artesunic acid with p-nitrobenzyl N, N diisopropylisourea at $80{ }^{\circ} \mathrm{C}$ for $2 \mathrm{~h}$ as reported by
Zou et al [15] and others [16]. However, their reaction time of $2 \mathrm{~h}$ is much longer than the 15 min recorded in this work. Also of importance is the 15 min reaction time in this experiment as against the IP method which requires at least 30 min reaction time [2].

A calibration curve constructed with our method at the absorbance at $290 \mathrm{~nm}$, showed linearity in the range $30-100 \mu \mathrm{g} / \mathrm{mL}$ for $\mathrm{DHA}$ and 500 $\mu \mathrm{g} / \mathrm{mL}$ for PNA, with an $r^{2}$ of 0.9987 . The wavelength of $290 \mathrm{~nm}$ was selected because the two absorption maxima in the UV region ( $205 \mathrm{~nm}$ and $230 \mathrm{~nm}$ ) were not suitable. Determination at $205 \mathrm{~nm}$ is subject to error since it is less than the cut-off point of methanol $(210 \mathrm{~nm})$, and at 230 $\mathrm{nm}$, the peak is not visible at low concentrations of the drug and reagent. Our detection limit (6 $\mu \mathrm{g} / \mathrm{mL}$ ) can be accounted for by the reduced reactivity of artemisinin moiety since it lacks reactive functional groups.

Validation studies carried out on the new method showed that the proposed method is precise and accurate, thus making the method suitable for routine analysis of dihydroartemisinin tablets. The suitability of this new method for the analysis of dosage forms (tablets) was further quantified in the statistical comparison between it and the IP (2003) method for analysis of dihydroartemisinin tablets with a P-value $=0.08$, showing no significant difference, therefore implying their equivalence (Table 1). On the 
whole, the proposed method offers the advantages over the current official method of a shorter reaction time, and also is more direct, simpler, and consists of fewer dilution steps.

\section{CONCLUSION}

A validated novel UV-spectrophotometric method has been developed for the assay of dihydroartemisinin tablets. The method is lowcost, precise, accurate and simpler than the current official method. It is therefore recommended as an alternative method for routine quality control of dihydroartemisinin tablets

\section{REFERENCES}

1. Olaniyi AA. Essential Medicinal Chemistry, $3^{\text {rd }}$ ed. Hope Publications, Ibadan. 2005; pp 404-429.

2. International Pharmacopoeia. 3rd.edn. Geneva: World Health Organization, 2003; pp 215-222.

3. White NJ. Clinical Pharmacokinetics and Pharmacodynamics of artemisinin derivatives. Trans R Soc Trop Med Hyg. 88 1994; supl 1: 541-543.

4. Martino R, Malet-Martino M, Gilard V. Counterfeit drugs: analytical techniques for their identification. Anal Bioanal Chem. 2010; 398: 77-92.

5. World Health Organization Guidelines for the treatment of malaria. http://www.who.int/malaria/docs/Treat mentGuidelines2006.pdf [accessed 6 Feb 2010]

6. loset JR, Kaur H. Simple field assays to check quality of current artemisinin-based antimalarial combination formulations. PLoS One $2009 \mathrm{Sep}$ 30; 4(9):e7270. www.plosone.org/article/info\% 3Adoi\%2F10.1371\%2Fjournal

7. Atemnkeng MA, Marchand E, Plaizier-Vercammem J. Assay of artemeter, methyparaben and propylparaben in a formulated paediatric antimalarial dry suspension. J Pharm Biomed Anal. 2007; 43: 727-732.

8. Gaudin $K$, Kauss $T$, Lagueny $A M$, Millet $P$, Fawaz $F$, Dubost JP. Determination of artesunate using reversed-phase HPLC at increased temperature and ELSD detection. J Sep Sci. 2009; 32: 231237.

9. Liu S, Tian N, Huang J, Liu Z. Simple and rapid microscale quantification of artemisinin in living Artemisia annua $L$. by improved gas chromatography with electron-capture detection. Biomed Chromatogr. 2009; 23: 1101-1107.

10. Christen $P$, Veuthey JL. New trends in extraction, identification and quantification of artemisinin and its derivatives. Curr Med Chem. 2001; 8: 18271839.

11. Green MD, Mount DL, Wirtz RA. Authentication of artemether, artesunate and Dihydroartemisinin anti malaria using a simple colorimetric method. Trop Med Int Health 2001; 6: 980-982

12. Idowu OR, Edwards G, Ward SA, Orme ML, Breckenridge AM. Determination of arteether in blood plasma by high performance liquid chromatography with ultraviolet detection after hydrolysis with acid. J Chromatogr. 1989; 493: 125-136.

13. Thomas CG, Ward SA, Edwards G. Selective determination in plasma of artemether and its major metabolite dihydroartemisinin by high performance liquid chromatography with UV detection. J Chromatogr. 1992; 583: 131-136.

14. Zhao SS, Zeng MY. Studies on the analysis of qinghaosu by high-pressure liquid chromatograph and spectrometry (HPLC). Planta Med. 1985, 51: 233 -237. www. ajtmh.org/content/70/2/128

15. Zou $A Q$, Xie $M$, Lou $X D$. Determination of artesunic acid after chemical derivatization with $O, p$ nitrobenzyl N,N diisopropylisourea by HPLC and UV absorption. J Chromatogr. 1987; 410: 217221.

16. Gabriels M, Plaizier-Vercammen J. Development of a reversed-phase thin-layer chromatography method for artemisinin and its derivatives. $J$ Chromatogr. Sci. 2004; 42: 341-347

17. United States Pharmacopeia 30/National Formulary 25. General Chapter 1225, Validation of compendial methods. Rockville, Md., USA, 2007

18. Miller JC, Miller JN. Method of Steepest Ascent. In: Statistics for Analytical Chemistry, 3 edn, Prentice Hall London. Ellis Horwood PTR. 1993; pp 103-104. 